\title{
DIFICULDADES, DESAFIOS E SUPERAÇÕES SOBRE EDUCAÇÃO EM SAÚDE NA VISÃO DE ENFERMEIROS DE SAÚDE DA FAMÍLIA
}

\author{
DIFFICULTIES, CHALLENGES, AND OVERCOMING IN HEALTH EDUCATION IN THE VIEW OF FAMILY \\ HEALTH NURSES
}

DIFICULTADES, RETOS Y SUPERACIONES SOBRE EDUCACIÓN EN SALUD EN LA VISIÓN DE ENFERMEROS DE SALUD FAMILIAR

\author{
Cinara Botelho Moutinho ${ }^{1}$ \\ Edmar Rocha Almeida ${ }^{2}$ \\ Maisa Tavares de Souza Leite ${ }^{3}$ \\ Maria Aparecida Vieira ${ }^{4}$
}

Resumo Este estudo apresenta dificuldades, desafios e superações dos enfermeiros da Estratégia Saúde da Família na prática da educação em saúde. Foram entrevistados oito profissionais de equipes de saúde da família do município de Montes Claros, Minas Gerais, tendo como instrumento de coleta de dados a entrevista não estruturada. Os dados coletados foram transcritos e analisados segundo a técnica da análise do discurso. Os resultados foram agrupados em categorias de análise. Na visão desses sujeitos, existem dificuldades no contexto do processo de trabalho da equipe, barreiras relacionadas à estrutura física $\mathrm{e}$ insuficiência de recursos materiais nas unidades de saúde. Eles relataram, também, os desencontros na relação com os usuários no desenvolvimento da educação em saúde. Percebe-se um movimento dialético da realidade, pois, ao mesmo tempo em que existem dificuldades a serem vencidas, há substanciais avanços com novas práticas, potencialmente transformadoras da realidade estudada. Considera-se a natureza dinâmica do processo de mudanças, com avanços e retrocessos, traduzindo uma realidade em constante devir. Palavras-chave educação em saúde; saúde da família; pesquisa qualitativa; enfermagem.
Abstract This study presents the difficulties, challenges, and overcoming of nurses of the Family Health Strategy in the practice of health education. Eight professionals from family health teams of the municipality of Montes Claros, state of Minas Gerais (Southeast Brazil), were interviewed based on unstructured interviews. The data were transcribed and analyzed pursuant to the discourse technique. The results were grouped into analysis categories. In these subjects' view, there are difficulties in the teamwork process, barriers in the physical structure, and a lack of material resources at the healthcare facilities. They also report inconsistencies in the relationship with the users when undertaking health education. A dialectical movement of reality is noted because, while there are difficulties to be overcome, substantial advances have been made with new practices that may potentially transform the reality being studied. The dynamic nature of the change process is taken into account, with its advances and setbacks, which translate into a reality that is constantly under construction. Keywords health education; family health; qualitative research; nursing. 


\section{Introdução}

A educação, como prática essencialmente humana, é um instrumento de intervenção na realidade que deve estar acima de qualquer transmissão de saberes, centrando-se na criação de um ambiente de compartilhamento propício para a formação humana. Vista como uma prática social, pode ser pensada como um modo de promover a reflexão e a consciência crítica das pessoas sobre sua situação de vida. Para tanto, deve estar pautada no diálogo, no qual o indivíduo é considerado como um ser potencialmente capaz de construir seu próprio caminho histórico (Freire, 1996).

Para Ceccim e Ferla (2009), o processo educativo envolve mais que uma estrutura didático-pedagógica, incluindo relações afetivas e sociais que compõem a aprendizagem, pois o local em que a educação acontece é um campo de aprendizado afetivo que se nutre das experiências vivas do estar junto, para possibilitar harmonia e prazer no aprender em coletividade.

No contexto da saúde, a prática educativa voltada aos usuários é considerada uma tecnologia para a concretização do Sistema Único de Saúde (SUS), porque permite o contato com recomendações e discussões que possibilitam aumentar a capacidade no autocuidado à saúde. Quando pautada em pressupostos, como equidade, participação popular e integralidade, torna-se eixo norteador para proteção, promoção, prevenção em saúde e programação local (Vasconcelos, Grilo e Soares, 2009).

Assim, a educação no contexto da prática de atenção à saúde, denominada educação em saúde, pode ser definida como o canal em que os saberes científicos produzidos nessa área atingem a vida cotidiana da população, possibilitando a melhoria da saúde e da qualidade de vida. Trata-se da prática em saúde que mais se aproxima do pensar e agir das pessoas, permitindo a construção de saberes por meio da interface entre usuários e profissionais, contextualizada pela cultura e afetividade. Deve estar, também, fundamentada nos aspectos emancipatório e político da constituição humana, não somente voltada para determinantes biológicos da saúde, mas incorporadora da formação para a cidadania (Alves, 2005; Vasconcelos, Grilo e Soares, 2009).

Na realidade da Estratégia Saúde da Família (ESF), educar em saúde torna-se uma atribuição em destaque dos profissionais que compõem a equipe, ressaltada pela Política Nacional de Atenção Básica. Historicamente o enfermeiro é o profissional-chave para esse processo, especialmente por sua formação mais próxima da educação, considerando, ainda, que não é possível cuidar sem educar, sem dialogar, sem ensinar e também aprender. A atuação do enfermeiro nessa prática exige análise crítica de seu papel como educador, devido a sua proximidade com esse fazer e com a população, posto que cuidar e educar são atribuições indissociáveis no processo de trabalho da enfermagem (Acioli, 2008; Brasil, 2012; Fernandes e Backes, 2010). 
Observa-se que, apesar da evolução histórica do conceito de educação em saúde e da produção científica sobre o tema, há ainda, no campo prático, substanciais avanços a serem alcançados, especialmente pelos entraves que a implantação dessa estratégia encontra na realidade dos serviços de saúde (Silva et al., 2010).

Desse modo, é relevante refletir sobre a prática educativa em saúde como produtora de cuidado e transformadora de contextos sociais e de vida, mas é preciso ir além e problematizar as barreiras que dificultam sua efetivação, seja no interior do trabalho da equipe, seja nos desencontros com a própria população.

Com base nessas reflexões elaborou-se o presente estudo, cujo objetivo é analisar dificuldades, desafios e superações na prática da educação em saúde, segundo enfermeiros da Estratégia Saúde da Família (ESF) em Montes Claros, Minas Gerais.

Espera-se que o resultado desta pesquisa torne visível a realidade da prática educativa, com seus avanços e retrocessos, e seja substrato para a reflexão dos profissionais enfermeiros, dos gestores dos serviços de saúde e demais membros da equipe de saúde da família dos cenários desta investigação.

\section{Aspectos metodológicos}

Trata-se de um estudo qualitativo e descritivo, ${ }^{5}$ pois, para alcançar o objetivo proposto, inseriu-se no universo da qualidade, representado pelos 'significados' e 'intencionalidades', imersos nos 'atos' e 'estruturas sociais' relacionados ao fazer educativo do enfermeiro no contexto da ESF, a fim de compreender a realidade de maneira dialética, nas relações entre a consciência e o material e em uma perspectiva histórica da formação humana (Freire, 2007a; Minayo, 2007). Considera-se que o espaço de produção da saúde é rico em vivências e significados forjados pelo embate no meio cultural e social do território e pela proposta de trabalho da equipe de saúde. E é desse conflito que a história dos profissionais e das pessoas é construída e as práticas em saúde são efetivadas.

Para o desvelamento das categorias empíricas, foram entrevistados oito enfermeiros vinculados às distintas equipes da ESF de Montes Claros, profissionais que possuem diversas atribuições, mas entre elas destaca-se a educação em saúde, parte histórica do fazer da enfermagem no contexto do cuidado primário (Fernandes e Backes, 2010). Assim, foram utilizados os seguintes critérios de inclusão: possuir ou estar cursando especialização em saúde da família na modalidade de residência; atuar na equipe de ESF pelo menos há um ano; desenvolver alguma modalidade de atividade educativa coletiva junto à comunidade e aceitar participar deste estudo. Os critérios 
descritos possibilitaram a realização das entrevistas com profissionais conhecedores da realidade de uma equipe de saúde da família e envolvidos tempo suficiente para possuir vivências do objeto foco de análise (Minayo, 2007).

Em relação ao número de entrevistas, utilizou-se o critério da saturação das informações, pois houve a repetição dos discursos transcritos, sinalizando que o objeto foi apreendido. Esse critério baseia-se na ideia de que existe um número limitado de versões da realidade, pois apesar de as experiências terem aspectos de unicidade para cada sujeito, as representações são forjadas em processos sociais (Minayo, 2007).

Percebeu-se que o perfil dos participantes do estudo é similar. Eles concluíram o curso de graduação nos anos de 2005 ou 2006 e estavam, em média, há quatro anos em atuação na ESF. Todos possuíam ou cursavam algum tipo de pós-graduação na área da saúde da família, com destaque para a residência multiprofissional. Quanto à instituição formadora, sete são egressos da Universidade Estadual de Montes Claros (Unimontes) e apenas um de outra instituição, também de Montes Claros.

O cenário da pesquisa, município de Montes Claros, é polo de crescimento regional e sede de região ampliada de saúde do Plano Diretor de Regionalização em Minas Gerais. Apresenta uma rede de saúde primária composta por equipes da ESF, do Programa de Agentes Comunitários de Saúde (Pacs) e centros de saúde tradicionais. No momento da coleta de dados, o município possuía 59 equipes de ESF e Pacs, entre urbanas e rurais, o que gera uma cobertura populacional de aproximadamente $50 \%$. Ressalta-se a existência, no município, do Programa de Residência Multiprofissional em Saúde da Família, promovido pela Unimontes, que insere profissionais residentes na rede da ESF. Como em outros cenários, a ESF enfrenta problemas estruturais e organiza seus processos de trabalho de modo incipiente. Um desses processos é a educação em saúde, organizada em atividades coletivas voltadas a grupos com patologias prioritárias, como hipertensos, diabéticos e portadores de transtornos mentais. Nota-se, também, a ocorrência de grupos voltados para determinados ciclos de vida, como gestantes, idosos e mães de crianças menores de cinco anos. Com base nos relatos dos entrevistados, percebeu-se que não havia uma regularidade na realização dos grupos educativos.

Como instrumento de coleta de dados, optou-se pela entrevista não estruturada, que permitiu uma descrição abrangente do objeto da investigação, além de favorecer o dialogismo, materializado pela tentativa de conservação e defesa das concepções dos entrevistados. Além disso, utilizou-se um diário de campo que permitiu aos entrevistadores o registro das percepções e condições locais de produção das entrevistas. Aos sujeitos, propôs-se a participação voluntária e anônima, com direitos documentados pela assinatura do termo de consentimento livre e esclarecido (Freire, 2007b; Minayo, 2007). 
Os dados foram coletados pela gravação do áudio e tratados segundo a técnica da análise do discurso. Dessa forma, as entrevistas gravadas em áudio foram divididas entre dois pesquisadores, sendo que cada um ficou responsável pela transcrição de quatro delas. Depois de finalizada essa etapa, as transcrições foram avaliadas pelos pares, de modo que foi possível revisar cada uma e identificar falhas no processo primário de transcrição, além de discutir e definir alguns trechos em que houve divergência ou não entendimento. Em seguida, as entrevistas foram lidas de modo profundo e exaustivo a fim de eliminar a possibilidade de ilusão da transparência, ultrapassando a interpretação óbvia que o texto apresenta. Esse passo possibilitou, ainda, a busca da discursividade do texto, na procura de desfazer a ilusão de que aquilo que foi dito apenas poderia ser daquela maneira, desnaturalizando-se a relação palavra-coisa. Para tanto, consideraram-se o contexto da produção do discurso registrado no diário de campo e, também, as condições históricas e materiais do cenário estudado (Minayo, 2007; Orlandi, 2001).

Gradativamente emergiram as formações discursivas comuns nas falas dos sujeitos, que foram materializadas em um esboço das categorias empíricas na busca pelas ideologias constituintes, pano de fundo para as formações discursivas. Nessa etapa, a releitura das entrevistas na íntegra e a correlação entre formações discursivas, totalidade do texto e suas condições de produção foram um procedimento permanente (Orlandi, 2001). Por fim, foi possível a construção de um mapeamento que facilitou a associação de ideias ao receber os recortes das falas categorizados de acordo com a formação discursiva e identificados por códigos indicativos dos sujeitos-falantes (El a E8), preservando, dessa maneira, seu anonimato.

Nesse sentido, buscou-se constituir categorias empíricas que desvelassem o cotidiano de trabalho relacionado à educação em saúde dos enfermeiros participantes e também contivessem formações ideológicas, na procura da discursividade do texto e de sua totalidade, especialmente nas relações dinâmicas e históricas (Minayo, 2007; Orlandi, 2001).

O projeto desta investigação foi apresentado ao Comitê de Ética em Pesquisa da Unimontes, aprovado sob o Parecer Consubstanciado n. 1.557/09.

\section{Resultados e discussão}

Dos resultados, emergiram três categorias empíricas desveladas das formações discursivas identificadas: o processo de trabalho em equipe; a realidade estrutural; e a relação com os usuários no processo educativo. Essas categorias não se encontram isoladas, mas se articulam umas às outras, demonstrando, desse modo, a totalidade do fenômeno estudado. 


\section{O processo de trabalho em equipe}

Um dos principais objetivos da ESF é estruturar os serviços para a abordagem integral de cada pessoa, considerando-a como sujeito em determinado contexto histórico, social e político, articulando suas vivências familiares, do meio ambiente e da sociedade (Ceccim e Ferla, 2009; Machado et al., 2007). Para tanto, faz-se necessária uma lógica inovadora de organização dos serviços, representada pelo trabalho em equipe e multiprofissional. Composta por, minimamente, enfermeiro, médico, auxiliar ou técnico em enfermagem e pelos agentes comunitários de saúde, a equipe de saúde da família é responsável pelo cuidado de saúde da população de um determinado território (Peduzzi, 2001; Campos, Faria e Santos, 2010).

Torna-se competência dessa nova equipe a construção do processo de trabalho coletivo, compartilhado entre profissionais com diferentes saberes, a fim de planejar, implementar e avaliar a promoção da saúde, materializada, sobretudo, por atividades educacionais (Faria et al., 2009). Entretanto, o que se observa nos discursos dos entrevistados é a fragmentação do trabalho em equipe:

Então, dependendo do profissional que vai fazer a reunião, a abordagem é acerca da atribuição daquele profissional. Por exemplo, os dentistas fazem uma reunião periódica, abordando algum tema de saúde bucal. Enfermeiros e médicos abordam os temas gerais, sobre hipertensão, atividade física, qualidade de vida, lazer e esporte. Vários temas são abordados, até mesmo os que não estão relacionados diretamente com a hipertensão, mas que são importantes (E7).

Observa-se que os fazeres ocorridos no decorrer da reunião educativa, realizada pelo entrevistado, permitem a visualização de uma abordagem multiprofissional em saúde, alicerçada nas diversas necessidades dos indivíduos (Brasil, 2008). Porém, o trabalho é visto na ótica da divisão de atribuições, ocasionando fragmentação do processo educativo, sendo que cada membro da equipe domina um campo de conhecimento relacionado às suas atribuições e o aplica de modo isolado. Precisa-se somar saberes, discutir condutas, problematizar a realidade para responder aos complexos problemas que envolvem a saúde, procurando trazer à tona as relações entre sujeitos sociais, conforme recomendam Vasconcelos, Grilo e Soares (2009). O trabalho descrito pelo entrevistado foi conceituado, por Peduzzi (2001), como agrupado, caracterizado pela fragmentação, sem evidências das correlações das diversas intervenções executadas, o que não leva a um objetivo assistencial comum e sim à justaposição de ações.

No entanto, o trabalho em equipe multiprofissional deve ter um espaço de atuação compartilhado entre os profissionais, além do campo de com- 
petências de cada membro da equipe, rico em possibilidades de troca e complementaridade. Nesse novo espaço, abrem-se oportunidades para a reconstrução dos fazeres, especialmente os educativos (Vasconcelos, Grilo e Soares, 2009). Os discursos a seguir revelam essa situação:

O grupo do médico, realmente, tem que ter uma abordagem diferente da do enfermeiro. A do enfermeiro, no meu ver, tem que conter uma abordagem baseada no autocuidado do paciente, por quê? Porque no grupo eu não vou dar diagnóstico de nenhuma doença, eu não vou prescrever nenhum medicamento (E4).

A gente variou os profissionais também, em relação aos temas. A gente convida, por exemplo, tem assunto de saúde bucal que é o dentista que faz. Cuidados com o recém-nascido geralmente o enfermeiro, sinais do parto, tipo de parto, geralmente o médico. E outros temas que são abordados. Então a gente varia a questão dos profissionais (E8).

Desse modo, o desafio que se apresenta para os atores envolvidos com a mudança do modelo assistencial é processar todo o trabalho no contexto da equipe, vislumbrando um novo paradigma, caracterizado pela cooperação de todos para com todos na busca de objetivos comuns (Araújo e Rocha, 2009; Vasconcelos, Grilo e Soares, 2009).

Para Campos, Faria e Santos (2010), parte da desarticulação das ações dos profissionais de saúde da família se deve às dificuldades na gestão do processo de trabalho, que é vista como um dos determinantes da assistência prestada. Fernandes e Backes (2010), em um estudo qualitativo com membros de uma equipe da ESF, com o objetivo de conhecer suas perspectivas sobre educação em saúde, mostram fatores dificultadores desse processo, como a existência de desarticulação, desordenamento e falta de diálogo no trabalho em equipe, que criam barreiras para a organização de um cuidado comum. Essa situação está presente no discurso do entrevistado:

Então, nossa equipe é multiprofissional ou pelo menos deveria ser. (...) E aí, se a gente não tem essa parceria com os outros, não dá conta, porque sobra muito para o enfermeiro. Às vezes, até outro profissional vira e fala assim: "mas o que você pensou para a reunião", sendo que ele que é responsável pela reunião (E1).

Para Acioli (2008), apesar de as ações de educação em saúde, desenvolvidas nos serviços de saúde da família, serem da responsabilidade de todos, é o enfermeiro o profissional que mais se identifica e se compromete com a função, pois seu fazer está muito mais próximo dela do que dos outros profissionais. 
$\mathrm{Eu}$ acredito que a prática educativa, muitas vezes, fica a cargo apenas de um profissional. (...) Fica nas costas do enfermeiro, que geralmente é quem faz as reuniões (E8).

(...) não dá conta, porque sobra muito para o enfermeiro (E1).

Esses discursos assemelham-se aos encontrados por Pavoni e Medeiros (2009) em estudo sobre o processo de trabalho das equipes de saúde da família no Rio Grande do Sul, no qual o enfermeiro é quem mais assume atividades e, por vezes, executa sozinho fazeres que poderiam ser compartilhados.

No entanto, existem contradições presentes, pois o discurso a seguir relata a prática com grupos de educação em saúde de modo integrado, com a participação de todos os membros da equipe ou da maioria deles:

(...) aí eles são realizados de maneira que 'todos' nós participamos: eu, enfermeira, a médica da equipe, que na verdade é a tutora, os agentes comunitários, o dentista, a técnica de higiene dental, todos participam (E1).

Apesar da contradição posta, o discurso seguinte aborda o fazer coletivo, complementar e interdependente, indicando a integralidade na oferta do cuidado voltado para o objetivo comum, alcançado pelo trabalho em equipe organizado, como preconizado por Araújo e Rocha (2009) e Fernandes e Backes (2010):

Então, mesmo sendo temas, ou específicos do dentista, do médico, (...) também a gente aborda, fica em conjunto, não tem, assim, só a questão específica do dentista, ele faz uma reunião abordando outros temas também, não só saúde bucal. Eu acho que isso é interessante na educação em saúde, é ter a participação! Ter uma equipe multidisciplinar mesmo para dar esses grupos (E8).

Percebe-se um movimento dinâmico entre os profissionais que, apesar das atribuições e dos saberes específicos de cada categoria, estão envolvidos nas fases e nos temas do processo educativo pautado na integralidade da pessoa. Somente trabalhando dessa forma obtém-se uma equipe genuinamente multiprofissional, preparada para lidar com a complexidade da prática educativa na ESF e, desse modo, reorganizadora do processo de trabalho em saúde, para permitir a acentuação da resolubilidade e da integralidade (Faria et al., 2009) - assim como o desenvolvimento e o fortalecimento da interdisciplinaridade, de um novo fazer dialógico em que todos possam ser sujeitos do processo (Fernandes e Backes, 2010; Freire, 2007a).

Entretanto, para Campos, Faria e Santos (2010), na prática, de maneira geral, o que se visualiza são equipes sobrecarregadas em seu dia a dia, com 
dificuldades para responder à demanda espontânea e organizar uma agenda de atendimento aos usuários, considerando que as atividades exigem planejamento, como a educativa. Essa situação se apresenta no depoimento seguinte:

Outra dificuldade, que ocorre às vezes, é o cronograma. A gente faz uma programação mensal e aparece algum imprevisto bem na data que foi programada determinada reunião. Então, é preciso saltar e reprogramar a reunião, o que dificulta a participação das pessoas, ou falta a um determinado compromisso para não prejudicar o andamento, o acontecimento das reuniões (E7).

Estudo realizado por Barbosa e colaboradores (2009), no estado de Minas Gerais, com o objetivo de descrever o perfil dos gerentes da ESF e suas atribuições, evidenciou que o enfermeiro na grande maioria dos casos realiza essa função, dividindo seu tempo entre a gestão e as atividades clínicas, como a educação em saúde, o que sobrecarrega o profissional. Jesus e colaboradores (2008), para caracterizar o discurso dos enfermeiros sobre a educação em saúde, realizaram um estudo com esses profissionais da ESF em Juiz de Fora (Minas Gerais), identificando, como fator dificultador para a realização das atividades educativas, a grande demanda pelo serviço, o que também ocorre no discurso do entrevistado desta investigação:

Então, acaba que tem dia que não tem jeito de fazer educação em saúde, por algum motivo, tipo ter que fazer pré-natal, ou então chega demanda espontânea no acolhimento (E1).

Parte dessa dificuldade surge pela característica de a ESF ser a porta de entrada do SUS. Assim, a ela é atribuído o acolhimento da demanda espontânea e programada de todas as pessoas adscritas em determinado território (Brasil, 2012). Segundo Villas Boas, Araújo e Timóteo (2008), em uma reflexão analítica sobre a prática educativa gerencial do enfermeiro na ESF, com base na literatura e na análise da realidade institucional em Natal (Rio Grande do Norte), são reais o excesso de trabalho e a alta demanda requerida do enfermeiro. Calomé, Lima e Davis (2008), em estudo qualitativo com enfermeiras da ESF de Porto Alegre (Rio Grande do Sul) com o objetivo de conhecer a concepção dessas profissionais sobre o desenvolvimento do trabalho em equipe, identificaram que esse excesso de fazeres dificulta o trabalho planejado em saúde da família.

\section{A realidade estrutural}

A ESF emprega, em seu trabalho, tecnologias de elevada complexidade e baixa densidade, que devem estar voltadas para a solução dos problemas 
de maior frequência e importância em seu território de responsabilidade. Nesse nível de atenção à saúde, utilizam-se tecnologias de maior complexidade, porém, de melhor custo/benefício quando comparadas com outros serviços, pois não requerem volume de aparatos tecnológicos ao se concentrarem em uma abordagem sociocultural da saúde. No entanto, mesmo que esteja apoiada em um modelo tecnológico menos denso, a ESF necessita de uma estrutura mínima para exercer seu papel adequadamente (Brasil, 2012; Minas Gerais, 2008).

Pode-se perceber essa realidade no discurso do entrevistado ao relatar as dificuldades relacionadas a recursos materiais em suas atividades educativas:

Atualmente, nós, aqui da equipe, nós não temos muitos recursos. Outro item importante para que os grupos deem certo são recursos disponíveis, recursos e instrumentos, e aqui a gente não tem muitos recursos (E4).

Melo, Santos e Trezza (2005), em investigação descritiva e qualitativa com profissionais de nível superior da ESF de São Sebastião (Alagoas), com o objetivo de verificar o entendimento destes sobre a educação em saúde, encontraram, como resultados, a denúncia de escassez de recursos didático-pedagógicos, como cartazes e audiovisuais, causando limitação no fazer educativo, à semelhança do percebido nesta investigação.

Pereira e Cervo (2006), em pesquisa qualitativa realizada em Feira de Santana (Bahia), que objetivou analisar a prática educativa de enfermeiros de unidades básicas de saúde, verificaram a carência ou total ausência de recursos materiais para fins didáticos. No citado estudo de Jesus e colaboradores (2008), também foi relatada a falta de investimentos em recursos materiais como barreira para o fazer educativo, limitando-se o desenvolvimento de ideias e estratégias dos profissionais. O depoimento seguinte trata dessa questão:

É mais de recurso material, que eu acredito que a maior dificuldade que às vezes a gente tem. As ideias são muito boas, mas às vezes tem ideias muito boas que dependem de maiores recursos e que a gente não consegue fazer por causa disso (E2).

Desse modo, a disponibilidade de material de apoio pedagógico, bibliográfico ou audiovisual, é fator que impõe barreiras à prática educativa, porém não a impede de acontecer, considerando que a prática educativa na ESF deve estar apoiada em um modelo social, imerso na cultura popular, a fim de sensibilizar as pessoas para a mudança no cuidado com a própria saúde (Vasconcelos, Grilo e Soares, 2009).

Além da escassez de recursos para a implementação das ações educativas, os sujeitos citam dificuldades de estrutura física que repercutem no processo de trabalho em saúde da família: 
Atualmente, nós estamos tendo um problema com espaço físico, a estrutura da unidade está um pouco danificada, nossa sala de reunião está com muita infiltração, mofada e com a ventilação prejudicada também (E7).

É conhecida a realidade da Estratégia Saúde da Família no estado de Minas Gerais, que apresenta como um dos nós críticos a precária infraestrutura física das unidades básicas, sendo necessária, por vezes, a utilização de imóveis adaptados às normas estabelecidas (Minas Gerais, 2008). A carência de infraestrutura espalha-se por todo o Brasil, pois dados de 2008 confirmam que cerca de $75 \%$ das unidades de saúde da família não apresentam estrutura mínima adequada e $18 \%$ são instaladas em casas alugadas e adaptadas (Barbosa, 2010). Sabe-se que a edificação da unidade básica é uma condição que contribui, totalmente ou pelo menos em parte, para o desenvolvimento do trabalho da ESF, como as reuniões educativas (Faria et al., 2009).

Segundo a Organização Mundial da Saúde (2008), a infraestrutura dos serviços de atenção primária é considerada como problema da atenção à saúde pública, compondo um conjunto de fatores que geram impacto negativo na prestação de serviços no mundo, e é uma das maiores dificuldades enfrentadas nesse setor. Para Villas Bôas, Araújo e Timóteo (2008), em estudo já referido, esse fato prejudica a autonomia das equipes e interfere fortemente no processo de trabalho. Também nos estudos citados de Jesus e colaboradores (2008) e de Melo, Santos e Trezza (2005) foi detectada essa dificuldade, pois os profissionais da equipe de saúde da família queixavam-se da falta de espaço para as atividades educativas.

Os discursos apresentam uma ESF que está longe de se consolidar porque não foram atendidas as condições materiais para que isso acontecesse. Esse fato contradiz o discurso oficial da ESF no Brasil, que a coloca como prioridade no contexto do SUS (Brasil, 2012; Mendes, 2012). Na realidade, o que se observa é a baixa valorização política, materializada pela atual política de financiamento. Além disso, observa-se a desvalorização econômica pelo pequeno valor que a Estratégia Saúde da Família agrega a atores sociais de força no palco sanitário. Dessa forma, identifica-se uma ideologia dominante que apresenta a ESF como forma simples e barata de assistência à saúde, quando na verdade requer recursos consideráveis para realizar sua função adequadamente (Mendes, 2012).

No entanto, mesmo diante de limitações com espaço físico e materiais, as atividades acontecem com a utilização de recursos próprios da comunidade:

(...) na comunidade não tem nenhuma área de lazer, só tem o salão da pastoral da criança, que é utilizado para fazer esse grupo. Então, às vezes, a gente depende também da casa de moradores, a casa do agente comunitário para trabalhar com esses grupos (E3). 
Essa situação também está presente em estudo qualiquantitativo de Maffacciolli e Lopes (2011) com profissionais de saúde, cujo objetivo foi conhecer o perfil das atividades de grupo desenvolvidas pela rede básica de saúde de Porto Alegre (Rio Grande do Sul), ao mostrar que os espaços físicos podem ser desfavoráveis, mas existe empenho de determinados trabalhadores em manter esse tipo de assistência, legitimando-a diante da equipe, da comunidade e da gestão local.

Há ainda outro estudo descritivo e qualitativo de Cervera, Parreira e Goulart (2011), com a finalidade de conhecer a percepção de enfermeiros vinculados à ESF de Uberaba (Minas Gerais) sobre a educação em saúde, que apresenta um cenário de práticas constantes nesse campo, mesmo diante de restrições, semelhante ao ocorrido na presente pesquisa.

Pinafo e colaboradores (2011), também em pesquisa qualitativa realizada com o objetivo de analisar as concepções de educação em saúde de profissionais de duas equipes de ESF do município de Santa Mariana (Paraná), verificaram que a educação em saúde encontra-se presente na rotina dos profissionais de saúde da família.

\section{A relação com os usuários no processo educativo}

Todo processo de trabalho em saúde é realizado por agentes, sujeitos capazes de gerar uma ação de cuidado direcionada aos usuários. Existem contextos em que o usuário/sujeito é visto como objeto, um receptor de determinadas ações; entretanto, há outros em que é também responsável pela ação. Quando o processo é a prática educativa, é interessante superar a ideia de objeto e pensar em todos como sujeitos (Faria et al., 2009). Com base nessas afirmações, infere-se que é necessária a adesão do educando à proposta educativa, expressão de seu interesse pelo aprendizado:

Bem, a prática de educação em saúde aqui na unidade, sobretudo a minha, não está ainda bem consolidada, (...) bem programada, por vários motivos. Aqui na nossa unidade (...) a nossa população não adere muito aos grupos de educação em saúde, então a gente tem certa dificuldade em fazer com que os nossos usuários, principalmente aquelas pessoas portadoras de doenças crônicas, participem dos grupos (E4).

Estudo de Fernandes e Backes (2010) mostra que, na visão dos profissionais de saúde da família, os sentimentos e as experiências desfavoráveis em relação à participação da comunidade nas ações educativas geram desmotivação e criam uma barreira interna para a organização da educação em saúde. Semelhantes são os achados de Silva, Dias e Rodrigues (2009), em pesquisa qualitativa realizada na ESF de Sobral (Ceará) com o objetivo de 
analisar a práxis educativa de enfermeiros, ao identificarem, nos relatos dos profissionais da equipe de saúde, a desvalorização da educação em saúde pela comunidade, que não atribui utilidade aos fazeres educativos. O relato a seguir contribui para essa análise:

E outra dificuldade, também, às vezes em alguns grupos é a participação, a adesão das pessoas, porque muitos consideram que não precisam participar de grupo, outros não gostam de participar (E7).

Em estudo realizado no estado do Paraná por Roecker, Budó e Marcon (2012), com o objetivo de conhecer as dificuldades e perspectivas de mudanças que os enfermeiros da ESF identificam no desenvolvimento de ações educativas, foi constatada resistência da população às atividades educativas, o que na verdade representa a aversão ao novo modelo assistencial que contrapõe a ideologia biomédica ainda dominante. Da mesma forma, Cervera, Parreira e Goulart (2011) e Jesus e colaboradores (2008) afirmam, em seus respectivos estudos, a desmotivação dos atores envolvidos com a prática educativa em saúde, como expressa o seguinte discurso:

Mas o grupo para educação mesmo, orientação, então, a gente nota que os pacientes não aderem muito (...) porque a população ainda tem uma visão dos grupos de educação em saúde talvez um pouco deturpada, porque até um tempo atrás nos grupos eram usadas metodologias bem cansativas. Aquelas palestras, aquelas aulas expositivas, onde o paciente só escutava orientação, conceitos que ele talvez já tinha escutado, escutava sempre, e sempre a mesma coisa. Então a população, aqui, não adere muito aos grupos de educação em saúde (...). A gente já teve momentos de marcar grupos e vir só, sei lá, três, dois, quatro pacientes, e a gente chamar bem mais (E4).

Percebe-se, nesse discurso, falta de motivação dos usuários em razão de experiências impositivas e prescritivas que, segundo Freire (2007a), desestimulam o educando a aprender. Como recomendam Acioli (2008) e Pereira e Cervo (2006), uma estratégia para solucionar o problema apresentado é permitir aos educandos escolherem os temas a serem trabalhados. Assim, é possível construir uma conduta pautada nas necessidades das pessoas, nas suas experiências e na realidade concreta com suas multiplicidades culturais ligadas ao processo de saúde-doença e da própria vida, facilitando o aprendizado significativo e tornando as programações mais atraentes e efetivas, como informa um entrevistado:

Eu acredito que é mais essa questão de repetição mesmo, sabe! Assim, que 'eu acho que a pessoa vai falar sempre a mesma coisa' (...). Só que aí, igual eu falei a 
respeito da gente tentar variar um pouco os temas para não falar só, por exemplo, sobre hipertensão e diabetes. (...) eu acho que isso leva eles a ficarem sem querer voltar ao grupo, porque já sabem o que a gente vai falar (E8).

Na visão de Vasconcelos, Grilo e Soares (2009), a manutenção de um grupo educativo é um grande desafio em seus aspectos de quantidade, como frequência e número de membros, e qualidade, pela efetividade e participação ativa dos usuários. Entretanto, não é tarefa impossível e requer planejamento, fundamentação teórica adequada e esforço profissional. A perseverança e o esforço profissional são relatados no discurso a seguir:

E a gente, assim, percebe que uma grande dificuldade com o decorrer do tempo, pois a equipe já tem quatro anos, é o fato de ficar um pouco desgastada essa relação nos grupos. Os temas começam a ser saturados, a gente fica com uma determinada dificuldade de trabalhar com determinados temas e as dúvidas vão acabando aos poucos, então há grande dificuldade na participação dos usuários, é que muita coisa fica repetitiva e alguns se sentem desestimulados quanto a essa questão, mas a gente sempre busca novas sugestões da demanda deles, para que isso não ocorra, ou ocorra com a proporção menor (E7).

Além da metodologia e da saturação de temas, outros fatores reforçam a desvalorização dos trabalhos educativos, conforme estudos de Jesus e colaboradores (2008) e Pinafo e colaboradores (2011), nos quais os sujeitos associam a falta de interesse da comunidade pelos grupos educativos à sua compreensão da saúde ainda enraizada em uma perspectiva biomédica. O relato a seguir corrobora essa interpretação:

Então esses pacientes acham que não estão sentindo nada, então não precisam fazer dieta, não precisam aderir à medicação e muito menos vir aos grupos (E6).

Esse fato ocorre e pode gerar conflitos na forma de compreender determinadas situações. Desse modo, a equipe tem dificuldades em entender as concepções de mundo e em compreender o que é a saúde da comunidade. Ao mesmo tempo, a comunidade tem limitações para entender a proposta de trabalho da equipe de saúde, como relatam Vasconcelos (2008) e Vasconcelos, Grilo e Soares (2009). Nesse sentido, há a necessidade de uma abordagem diferenciada, pautada nas relações sociais e na perseverança:

Então a gente chama para consulta de enfermagem, a gente vai à casa, faz visita, convida para grupo, aí alguns desses, realmente, eles não têm coragem de falar isso para o enfermeiro, mas geralmente com o ACS eles falam: "Ah, eu não vou no grupo não, porque eu já sei as coisas que vão falar ali e eu não quero mudar" (E6). 
No entanto, mesmo compreendendo a proposta de saúde da equipe, às vezes a decisão do usuário é de não participar de uma atividade educativa, pois não deseja mudar. É nesse momento que a posição do educador deve apresentar-se aberta, nutrida pela fé e pela esperança ao oportunizar outras abordagens, como a visita domiciliária e a consulta de enfermagem, necessárias à criação de um ambiente de empatia, capaz de superar as diferenças e estabelecer um respeito harmonioso, representativo de posição genuinamente democrática (Freire, 2007a). A construção desses laços sociais democráticos é um desafio para o SUS, que necessita de um ativo engajamento de todos os atores para a sonhada mudança do paradigma de saúde (Faria et al., 2009).

Merhy (2002) propõe que, no trabalho vivo em saúde, seus atores possam reproduzir modelos já instituídos ou tornarem-se instituintes de práticas renovadas, a partir de cada momento e das necessidades surgidas. Assim, há ocasiões em que se deve protagonizar mudanças, trilhar caminhos antes não percebidos, gestar processos novos como força de mudança dos fazeres cristalizados, como expressa um enfermeiro entrevistado:

Talvez as gestantes multíparas já considerem que saibam de tudo e não têm necessidade de vir no grupo, então a gente tem que repensar. Talvez o erro seja nosso de estar trabalhando questões que essas mães já sabem (E6).

No estudo de Fernandes e Backes (2010), também são relatadas dificuldades da equipe na abordagem do trabalho educativo, sugerindo a necessidade de se repensar o processo. Em estudo de Roecker, Budó e Marcon (2012), já citado, são relatados pelos enfermeiros a necessidade de constante aprimoramento, por meio de cursos, estudos e leituras, por acreditarem que a educação permanente é uma alternativa para superar as dificuldades com a educação em saúde. Segundo Cervera, Parreira e Goulart (2011), em seu estudo já referido, o campo da educação em saúde caminha para novos desafios e amadurecimentos, presentes no enunciado a seguir: "Mas é um desafio, porque, com o passar do tempo, a gente tem que usar muito a criatividade para estar desenvolvendo novas atividades" (E7).

Para Villas Bôas, Araújo e Timóteo (2008), o trabalho na Estratégia Saúde da Família é um desafio à enfermagem em todos os seus fazeres, necessitando sempre de renovação de práticas, redirecionamento de caminhos e criação de novas condutas diante de novos paradigmas. Na visão de Roecker, Budó e Marcon (2012), para realizar a prática educativa na ESF é necessário que os profissionais acreditem e apostem em seu trabalho, pois os obstáculos existem, mas com empenho e dedicação é possível iniciar o processo de mudança.

De acordo com Mendes (2012), a mudança é não somente necessária, mas primordial para a sobrevivência da ESF, para transformá-la, de fato, na estratégia de reorientação da saúde no Brasil. Para tanto, faz-se necessário 
reconhecer suas limitações a fim de promover um adensamento tecnológico, que envolverá tecnologias leves com ênfase na cognição, como a educação em saúde, potencialmente promotoras de mudanças que levam ao autocuidado por parte da população.

\section{Considerações finais}

Descrever o complexo universo em que a prática educativa em saúde acontece, a partir do olhar dos enfermeiros vinculados à Estratégia Saúde da Família, possibilitou conhecer melhor a realidade concreta, com suas peculiaridades e o papel de seus atores sociais, permitindo a elaboração de considerações e recomendações.

São inúmeras as barreiras impostas ao fazer educativo no cotidiano profissional da ESF, como a desarticulação do trabalho em equipe, com sinais de atuação individualizada e de sobreposição de ações; a carência de recursos de apoio ao processo educativo; as limitações de infraestrutura das unidades e a desvalorização da população, motivada pelo descrédito em relação à educação em saúde ou pela insatisfação com a metodologia de trabalho empregada. No entanto, contraditoriamente, evidencia-se que a educação em saúde se legitima, mesmo diante dessas dificuldades, pelo esforço dos profissionais em uma tentativa de trabalhar de modo integrado e efetivar suas ações, com a utilização de recursos da comunidade ou, simplesmente, pela perseverança ao continuar em frente, em um movimento de superação.

Assim, a realidade estudada demonstra seu devir e revela que a prática educativa acontece em meio a contradições entre um fazer tradicional e um novo que, aos poucos, se constrói apesar das diversas dificuldades, mostrando que essa prática é um desafio, nas dimensões do material e das ideias, para a atuação do enfermeiro em saúde da família.

Nessa perspectiva, a valorização dos profissionais que atuam nesses cenários é imprescindível, pois eles são sujeitos capazes de transpor barreiras e mudar a realidade a partir de seus fazeres. Tornam-se prudentes intervenções dos órgãos gestores do sistema municipal de saúde para a minimização das dificuldades relacionadas à estruturação da Estratégia Saúde da Família e à falta de recursos para a prática educativa. Essas intervenções irão facilitar o diálogo e a crítica, constituindo-se em um movimento potencialmente capaz de reestruturar as relações de trabalho desveladas, para possibilitar harmonia e prazer no aprender em coletividade. 


\section{Colaboradores}

Cinara Botelho Moutinho, Edmar Rocha Almeida e Maisa Tavares de Souza Leite trabalharam em conjunto na realização da pesquisa e da escrita do artigo. Maria Aparecida Vieira participou, também, na elaboração da escrita e na revisão do texto.

Resumen Este estudio presenta dificultades, retos y superaciones de los enfermeros de la Estrategia de Salud Familiar en la práctica de la educación en salud. Se entrevistaron a ocho profesionales de equipos de salud familiar del municipio de Montes Claros, Minas Gerais (Sureste de Brasil), usando la entrevista no estructurada como instrumento de recolección de datos. Los datos recogidos se transcribieron y analizaron usando la técnica de análisis del discurso. Los resultados se agruparon en categorías de análisis. En la visión de estos individuos, hay dificultades en el ámbito del proceso de trabajo del equipo, barreras relacionadas con la estructura física e insuficiencia de recursos materiales en las unidades de salud. Éstos relataron también los desequilibrios en la relación con los usuarios, en el desarrollo de la educación en salud. Se observa un movimiento dialéctico de la realidad, pues, si bien hay dificultades que superar, también hay avances sustanciales con nuevas prácticas, potencialmente transformadoras de la realidad estudiada. Se considera la naturaleza dinámica del proceso de cambio, con avances y retrocesos, lo que resulta en una realidad en constante devenir.

Palabras clave educación en salud; salud familiar; investigación cualitativa; enfermería. 


\section{Notas}

1 Universidade Estadual de Montes Claros, Montes Claros, Minas Gerais, Brasil.

Graduada em Enfermagem pela Universidade Estadual de Montes Claros.

<cinarabotelho@yahoo.com.br>

Correspondência: Rua Caiçara, 1.574, Sagrada Família, CEP 39550-000, Taiobeiras, Minas Gerais, Brasil.

2 Departamento de Saúde e Saneamento da Prefeitura de Taiobeiras, Minas Gerais, Brasil.

Especialista em Atenção Básica em Saúde da Família pela Universidade Federal de Minas Gerais. <edsky48@gmail.com>

3 Universidade Estadual de Montes Claros, Montes Claros, Minas Gerais, Brasil.

Doutora em Ciências pela Universidade Federal de São Paulo. <mtsiv@terra.com.br>

4 Universidade Estadual de Montes Claros, Montes Claros, Minas Gerais, Brasil.

Doutoranda em Ciências pela Universidade Federal de São Paulo. <di.vieira@ig.com.br>

5 Este artigo baseia-se na pesquisa intitulada "Educação em saúde na Estratégia Saúde da Família: a visão do enfermeiro e do usuário", financiada pela Fundação de Amparo à Pesquisa do Estado de Minas Gerias (Fapemig), como parte do Programa Institucional de Iniciação Científica (Proinic) da Universidade Estadual de Montes Claros, Montes Claros, Minas Gerais.

\section{Referências}

ACIOLI, Sonia. A prática educativa como expressão do cuidado de saúde pública. Revista Brasileira de Enfermagem, Brasília, v. 61, n. 1, p. 117-121, jan./fev. 2008.

ALVES, Vânia S. Um modelo de educação em saúde para o Programa Saúde da Família: pela integralidade da atenção e reorientação do modelo assistencial. Interface: Comunicação, Saúde, Educação, Botucatu, v. 9, n. 16, p. 39-52, set. 2004/fev. 2005.

ARAÚJO, Marize B. S.; ROCHA, Paulo M. Saúde da família: mudando práticas? Estudo de caso no município de Natal (RN). Ciência
\& Saúde Coletiva, Rio de Janeiro, v. 14, supl. 1, p. 1.439-1.452, 2009.

BARBOSA, Allan C. Q. Saúde da família no Brasil: situação atual e perspectivas, estudo amostral 2008. Belo Horizonte: Faculdade de Ciências Econômicas/UFMG, 2010. Mimeografado.

BARBOSA, Allan C. Q. et al. Gestores de unidades básicas de saúde e práticas de gestão: retrato censitário de Minas Gerais. Belo Horizonte: Observatório de Recursos $\mathrm{Hu}$ manos em Saúde/Faculdade de Ciências Econômicas da UFMG, 2009. 
BRASIL. Ministério da Saúde. Secretaria de Gestão Estratégica e Participativa. Politica Nacional de Gestão Estratégica e Participação no SUS. 2. ed. Brasília: Ministério da Saúde, 2008. (Série B, Textos Básicos de Saúde).

. Ministério da Saúde. Secretaria de Atenção à Saúde. Departamento de Atenção Básica. Política Nacional de Atenção Básica. Brasília: Ministério da Saúde, 2012. (Série E, Legislação em Saúde).

CALOMÉ, Isabel C. S.; LIMA, Maria A. D. S.; DAVIS, Roberta. Visão de enfermeiras sobre as articulações das ações de saúde entre profissionais de equipes de saúde da família. Revista da Escola de Enfermagem da USP, São Paulo, v. 42, n. 2, p. 256-261, 2008.

CAMPOS, Francisco C. C.; FARIA, Horácio P.; SANTOS, Max A. Planejamento e avaliação das ações de saúde. 2. ed. Belo Horizonte: Nescon/UFMG, Coopmed, 2010. (Caderno de Estudos do Curso de Especialização em Atenção Básica em Saúde da Família).

CECCIM, Ricardo B.; FERLA, Alcindo A. Educação em saúde: ensino e cidadania como travessia de fronteiras. Trabalho, Educação e Saúde, Rio de Janeiro, v. 6, n. 3, p. 443-454, nov. 2008/fev. 2009.

CERVERA, Diana P. P.; PARREIRA, Bibiane D. M.; GOULART, Bethania F. Educação em saúde: percepção dos enfermeiros da atenção básica em Uberaba (MG). Ciência \& Saúde Coletiva, Rio de Janeiro, v. 16, supl. 1, p. 1.547-1.554, 2011.

FARIA, Horácio P. et al. Processo de trabalho em saúde. Belo Horizonte: Nescon/UFMG, Coopmed, 2009 (Caderno de Estudos do Curso de Especialização em Atenção Básica em Saúde da Família).

FERNANDES, Maria C. P.; BACKES, Vânia M. S. Educação em saúde: perspectivas de uma equipe da Estratégia Saúde da Família sob a óptica de Paulo Freire. Revista Brasileira de Enfermagem, Brasília, v. 63, n. 4, p. 567-573, jul./ago. 2010.
FREIRE, Paulo. Pedagogia da autonomia: saberes necessários à prática educativa. 9. ed. São Paulo: Paz e Terra, 1996.

Política e educação. 8. ed. Indaiatuba: Villa das Letras, 2007a.

Pedagogia da esperança: um reencontro com a pedagogia do oprimido. 14. ed. São Paulo: Paz e Terra, 2007b.

JESUS, Maria C. P. et al. O discurso do enfermeiro sobre a prática educativa no Programa Saúde da Família em Juiz de Fora, Minas Gerais, Brasil. Revista APS, Juiz de fora, v. 11, n. 1, p. 54-61, jan./mar. 2008. Disponível em: <www.ufjf.br/nates/files/2009/ 12/054-061.pdf>. Acesso em: 31 mar. 2009.

MACHADO, Maria F. A. S. et al. Integralidade, formação de saúde, educação em saúde e as propostas do SUS: uma revisão conceitual. Ciência \& Saúde Coletiva, Rio de Janeiro, v. 12, n. 2, p. 335-342, 2007.

MAFFACCIOLLI, Rosana; LOPES, Marta J. M. Os grupos na atenção básica de saúde de Porto Alegre: usos e modos de intervenção terapêutica. Ciência \& Saúde Coletiva, Rio de Janeiro, v. 16, supl. 1, p. 973-982, 2011.

MELO, Gilberto; SANTOS, Regina M.; TREZZA, Maria C. S. F. Entendimento e prática de ações educativas de profissionais do Programa Saúde da Família de São Sebastião-AL: detectando dificuldades. Revista Brasileira de Enfermagem, Brasília, v. 58, n. 3, p. 290-295, maio/jun. 2005.

MENDES, Eugênio V. O cuidado das condições crônicas na atenção primária à saúde: o imperativo da consolidação da Estratégia da Saúde da Família. Brasília: Organização Pan-Americana da Saúde, 2012.

MERHY, Emerson E. Saúde: a cartografia do trabalho vivo. São Paulo: Hucitec, 2002.

MINAS GERAIS. Implantação do Plano Diretor de Atenção Primária à Saúde: redes de atenção à saúde. Belo Horizonte: Escola de Saúde Pública do Estado de Minas Gerais, 2008. (Guia do Tutor/Facilitador). 
MINAYO, Maria C. S. O desafio do conhecimento: pesquisa qualitativa em saúde. 10. ed. São Paulo: Hucitec, 2007.

ORGANIZAÇÃO MUNDIAL DA SAÚDE (OMS). Cuidados de saúde primários: agora mais que nunca. Relatório Mundial de Saúde 2008. Brasília: OMS, 2008.

ORLANDI, Eni P. Análise do discurso: princípios \& procedimentos. 3. ed. Campinas: Pontes, 2001.

PAVONI, Daniela S.; MEDEIROS, Cássia R. G. Processos de trabalho na equipe Estratégia de Saúde da Família. Revista Brasileira de Enfermagem, Brasília, v. 62, n. 2, p. 265-271, mar./abr. 2009.

PEDUZZI, Marina. Equipe multiprofissional de saúde: conceito e tipologia. Revista de Saúde Pública, São Paulo, v. 35, n. 1, p. 103-109, 2001.

PEREIRA, Ana P. C. M.; CERVO, Maria L. S. A enfermeira e a educação em saúde: estudo de uma realidade local. Revista Baiana de Saúde Pública, Salvador, v. 30, n. 1, p. 7-18, jan./jun. 2006. Disponível em: <http:// bases.bireme.br/cgi-bin/wxislind.exe/iah/ online/?IsisScript=iah/iah. $x$ is $\&$ src $=$ google $\&$ base $=$ LILACS\&lang $=$ p\&nextAction $=\operatorname{lnk} \&$ exprSearch $=455153$ \&indexSearch $=$ ID $>$. Acesso em: 31 mar. 2009.

PINAFO, Elisângela et al. Relações entre concepções e práticas de educação em saúde na visão de uma equipe de saúde da família. Trabalho, Educação e Saúde, Rio de Janeiro, v. 9, n. 2, p. 201-221, jul./out. 2011.
ROECKER, Simone; BUDÓ, Maria L. D.; MARCON, Sônia S. Trabalho educativo do enfermeiro na Estratégia Saúde da Família: dificuldades e perspectivas de mudanças. Revista da Escola de Enfermagem da USP, São Paulo, v. 46, n. 3, p. 641-649, 2012.

SILVA, Cheila P.; DIAS, Maria S. A.; RODRIGUES, Angelo B. Práxis educativa em saúde dos enfermeiros da Estratégia Saúde da Família. Ciência \& Saúde Coletiva, Rio de Janeiro, v. 14, supl. 1, p. 1.453-1.462, 2009.

SILVA, Cristiane M. C. et al. Educação em saúde: uma reflexão histórica de suas práticas. Ciência \& Saúde Coletiva, Rio de Janeiro, v. 5, n. 15, p. 2.539-2.050, 2010.

VASCONCELOS, Eymard M. Educação popular e a atenção à saúde da família. 4. ed. São Paulo: Hucitec, 2008.

VASCONCELOS, Mara; GRILO, Maria J. C.; SOARES, Sônia M. Práticas pedagógicas em atenção primária à saúde: tecnologias para abordagem ao indivíduo, família e comunidade. Belo Horizonte: Nescon/UFMG, Coopmed, 2009. (Caderno de Estudos do Curso de Especialização em Atenção Básica em Saúde da Família).

VILLAS BÔAS, Lygia M. F. M.; ARAÚJO, Marize B. S.; TIMÓTEO, Rosalba P. S. A prática gerencial do enfermeiro no PSF na perspectiva da sua ação pedagógica educativa: uma breve reflexão. Ciência \& Saúde Coletiva, Rio de Janeiro, v. 13, n. 4, p. $1.355-1.360,2008$.

Recebido em 26/04/2012

Aprovado em 22/07/2013 